\title{
Capital social e desenvolvimento econômico: um estudo bibliométrico
}

\author{
Munique Rech \\ Universidade de Caxias do Sul (UCS) \\ Roberto Clamer \\ Universidade de Caxias do Sul (UCS) \\ Sandra Regina Isoton Terribile \\ Universidade de Caxias do Sul (UCS) \\ Janaina Macke \\ Universidade de Caxias do Sul (UCS)
}

\begin{abstract}
Resumo
O capital social contribui com o desenvolvimento das comunidades, uma vez que aspectos da cultura interagem com o desenvolvimento econômico. Porém, essa relação entre capital social e desenvolvimento econômico é recente na literatura, sendo reconhecida apenas após a definição de capital social feita por Robert Putnam, em 1995. O desenvolvimento até então considerava apenas variáveis econômicas, não abordando o capital social. O objetivo deste estudo é analisar a produção acadêmica sobre a relação entre capital social e desenvolvimento econômico, os principais autores que tratam o assunto, como evoluíram no tempo e seus desafios. Para tanto, foi desenhada uma pesquisa bibliométrica de caráter exploratório, na base de dados Science Direct. A pesquisa revelou 76 artigos, 16 dos quais foram escolhidos a partir do critério de livre acesso (os demais tinham o acesso restrito ao pagamento monetário). A análise da produção acadêmica revelou que esses temas começaram a ser tratados conjuntamente no ano de 2011, tendo o seu ápice em 2016, o que revela ser um assunto recente. Além disso, evidenciou-se que a maioria dos artigos é constituída de obras estrangeiras, o que pode estar relacionado à restrição de estudos e obras nacionais sobre o tema.
\end{abstract}

Palavras-chave | Bibliometria; capital social; desenvolvimento econômico.

Código JEL | I29; O10; R19. 


\title{
SOCIAL CAPITAL AND ECONOMIC DEVELOPMENT: A BIBLIOMETRIC STUDY
}

\begin{abstract}
The social capital contributes to the development of communities, since aspects of culture interact with economic development. However, this relationship between social capital and economic development is recent in the literature, and it is recognized only after the definition of social capital made by Robert Putnam, in 1995. Economic development was hitherto treated only considering economic variables, does not address the capital. Thus, the aim of this study is to analyze the academic literature on the relationship between social capital and economic development. The main authors, who deal with the subject, were evolved over time and its challenges. For this, a bibliometric research exploratory character was drawn in Science Direct database. The survey revealed 76 articles, of which 16 were chosen at the discretion of free access to the work, since the others had restricted access to payment. The analysis of academic research revealed that these issues began to be treated together in 2011, and its production peak in 2016, which turns out to be a recent issue. Moreover, it was shown that most of the articles are foreign works, which may be related to the restriction of national studies and works on the subject.
\end{abstract}

Keywords | Bibliometrics; economic development; middle social capital.

JEL-Code | I29; O10; R19.

\section{CAPITAL SOCIAL Y DESARROLLO ECONÓMICO: UN ESTUDIO BIBLIOMÉTRICO}

\section{Resumen}

El capital social contribuye al desarrollo de las comunidades, ya que los aspectos de la cultura interactúan con el desarrollo económico. Sin embargo, esta relación entre el capital social y el desarrollo económico es reciente en la literatura, y se reconoce sólo después de la definición de capital realizada por Robert Putnam, en 1995. El desarrollo hasta ahora ha considerado las variables económicas, sin ocuparse del capital social. El objetivo de este estudio es analizar la literatura académica sobre la relación entre el capital social y el desarrollo económico, los principales autores que tratan el tema, cómo ha evolucionado con el tiempo y sus desafíos. Para ello, se efectuó una investigación bibliométrica de carácter exploratoria, en base a los aportes de la base de datos Science Direct. La búsqueda relevó 76 artículos, de los cuales 16 fueron elegidos, a partir del libre acceso a la obra (los otros tenían restringido el acceso por pago). El análisis de la producción académica reveló que estos temas comenzaron a ser tratados conjuntamente en 2011, con un pico de producción en 2016, lo que resulta ser un asunto reciente. Por otra parte, se demostró que la mayoría de los artículos son obras extranjeras, que pueden estar relacionados con la restricción de los estudios nacionales y los trabajos sobre el tema.

Palabras-clave | Bibliometría; capital social; desarrollo económico.

Código JEL | I29; O10; R19. 


\section{Introdução}

O capital social é a base para o desenvolvimento econômico, como está descrito na maioria dos artigos que tratam do assunto. Contudo, qual a produção científica que a base de dados da Science Direct indexa sobre o tema capital social relacionado ao desenvolvimento econômico?

Para responder a essa questão foi desenvolvido esse estudo bibliométrico, a fim de descobrir não apenas quantos artigos científicos foram desenvolvidos e que abordam os referidos temas, mas também no intuito de analisar os artigos que permitem acesso (open access journal) da referida base de dados para verificar informações como: principais autores citados, ano de produção, idiomas das publicações, principais palavras e termos utilizados.

Diante dessa análise foi percebida a necessidade de validar os temas de pesquisa em questão, para ratificar o quanto estão inter-relacionados e por qual motivo possuem essa relação, por isso foi estudado e embasado nas teorias relacionadas com capital social e desenvolvimento econômico, com o objetivo de identificar a convergência que sustenta a interdependência lógica entre esses temas.

O capital social pode aparecer sob muitas formas - confiança, normas e cadeias de relações sociais - e todas estas formas são recursos cuja oferta aumenta com o uso, em vez de diminuir, e que se esgotam se não forem utilizados (HIRSCHMAN, 1981). Existe vínculo entre o capital social e o desenvolvimento econômico, uma vez que esse último estabelece essencialmente o processo histórico de crescimento sustentado da renda ou do valor adicionado por indivíduo, implicando a melhoria do padrão de vida da população de um determinado meio social (SCHUMPETER, 1961).

Segundo Coleman (1988), para que haja desenvolvimento é essencial que haja um processo de crescimento da renda por habitante, ou do produto agregado por habitante, ou da produtividade. Não existe desenvolvimento sem que a produção e a renda média cresçam.

\section{Referencial teórico}

\section{Capital social}

O capital social é advindo dos indivíduos e pertence à sociedade, que aproveita os benefícios gerados dele (SOARES; ABREU; NAVAES, 2010). O capital social é produzido coletivamente e é originado das relações sociais das comunidades, 
porém, seus benefícios não podem ser antecipadamente mensurados (MARTELETO; SILVA, 2004).

De acordo com Putnam (2002), o capital social aborda características da organização social, tais como confiança, normas e sistemas, as quais colaboram com o crescimento da eficiência da sociedade, promovendo ações coordenadas. Soares, Abreu e Navaes (2010) corroboram com Putnam, afirmando que as organizações sociais, os valores comuns, a cooperação e a sinergia são fatores importantes para a evolução do desenvolvimento. Portanto, a sociedade que tem capital social torna-se fortalecida quanto à tomada de decisões e a execução de ações colaborativas que beneficiam toda a comunidade (ALVES; BASTOS, 2011). A cooperação espontânea é incentivada em sociedades com capital social (PUTNAM, 2002).

O capital social auxilia aqueles mutuários que não têm acesso aos mercados regulares de crédito, atuando como uma espécie de garantia (PUTNAM, 2002). Assim, contribui com o acesso ao crédito para os mutuários não convencionais. De acordo com Putnam (2002), os agentes que não dispõem de bens físicos para fornecer como garantia, podem empenhar suas relações sociais. O autor afirma que o capital social serve para ampliar o acesso ao crédito e eficiência com a qual os mercados operam.

Para Marteleto e Silva (2004), o capital social pode ser definido como um conjunto de redes e normas, que visa à redução dos riscos decorrentes das relações entre desconhecidos e dos custos de transação. Porém, ainda conforme os autores, a sua mensuração não ocorre de maneira fácil, pois torna-se difícil evidenciá-lo, uma vez que está fortemente aderido às redes de relações sociais. Estando associado ao desenvolvimento, a sua expansão ou modificação pode afetar o bem-estar de seus componentes (MARTELETO; SILVA, 2004).

A expressão capital social é muito popular e aplicada no campo da sociologia (PORTES, 1998). Putnam (1995) aproveitou um conceito sociológico antigo, o de redes sociais, para explicar e também definir o termo capital social sob a lente econômica. Mais tarde, Grootaert (1998) destaca que o conceito de capital social é a ligação que faltava para descrever os diferentes níveis de desenvolvimento. Foi da definição de Putnam (1995) que o capital social ficou sendo reconhecido e colocado sobre pensamento econômico e desenvolvimento. Moraes (2003) elucida que diversos autores que abordam o capital social acreditam que este tema é promissor e emergente modelo teórico que pode transformar-se em um importante instrumento para o estudo de desenvolvimento territorial. 


\section{Desenvolvimento econômico e capital social}

O capital social interfere no desenvolvimento econômico. Frederking (2002) afirma que a cultura interage com aspectos do desenvolvimento econômico. Porém, é considerada recente a participação do tema capital social com o crescimento ou desenvolvimento econômico (SOARES; ABREU; NAVAES, 2010). Os modelos de crescimento econômico consideravam apenas variáveis econômicas como determinantes do processo, como as de capital físico, humano e tecnológico (SOARES; ABREU; NAVAES, 2010). Os investimentos realizados para a ampliação do capital social, tal como o capital humano ou financeiro, devem possibilitar retornos ou benefícios, servindo de base para o desenvolvimento, assunto que tem sido amplamente pesquisado (MARTELETO; SILVA, 2004).

De acordo com Soares, Abreu e Navaes (2010), através das interações da sociedade ocorrem alterações no desempenho dessas comunidades, que passam a possuir um novo capital, denominado capital social. Os autores, em seu estudo, buscam verificar a maneira de interação conjunta das famílias para que alcancem estágio mais elevado de desenvolvimento econômico. Eles afirmam que não é apenas o Governo o responsável pelo desenvolvimento econômico, mas os indivíduos contribuem para que ocorra. Os agentes de desenvolvimento são os cidadãos, não agindo isoladamente, mas em forma de comunidade (SOARES; ABREU; NAVAES, 2010).

Foi com a definição de Putnam sobre capital social que ele passa a integrar o pensamento econômico sobre o desenvolvimento (SOARES; ABREU; NAVAES, 2010). A partir de então, o tema passa a ser abordado pelos pesquisadores do desenvolvimento econômico. Há um consenso de que o capital social é relevante para os pensadores do desenvolvimento econômico (SOARES; ABREU; NAVAES, 2010).

O capital social pode afetar o volume de negócios e o crédito, interferindo no desenvolvimento econômico. De acordo com Lima e Shirota (2005), a falta de informação sobre determinado risco de crédito pode ser suprida por um elevado capital social, que irá proporcionar mais segurança na concessão de crédito aos tomadores. Ainda de acordo com os autores, quanto mais informação ou maior quantidade de capital social, maior será o volume de negócios, pois a soma de informação e capital social resulta em confiabilidade. Marteleto e Silva (2004) também atribuem o acesso à informação com um elemento central para o desenvolvimento econômico e social em comunidades. De acordo com os autores, a capacidade de obter informações compõe o capital relacional dos indivíduos e grupos.

Áreas como a sociologia e a economia têm interesse sobre o capital social, uma vez que há evidências de que ele pode ser usado com a finalidade de reduzir a 
pobreza, ampliando o desenvolvimento e o bem-estar social (MARTELETO; SILVA, 2004). Para Adiseshiah (1970), o crescimento acontece por transformação e mudança, da mesma forma que a mudança é o resultado do crescimento. Em análise, o desenvolvimento é uma maneira de humanismo, pois seu foco é servir ao homem, tanto moral, material como prático.

Porém, para Hewlett (1981) o desenvolvimento econômico é basicamente conceituado para um aumento na renda per capita de uma nação, cujo enfoque principal é o desenvolvimento na obtenção de melhorias na alimentação, na saúde, na educação e na ampliação de oportunidades. Esse conceito de desenvolvimento significa a mudança nas estruturas econômicas da sociedade, para assim atingir um novo nível de capacidade produtiva.

Para Hirschman (1981), o desenvolvimento econômico é uma área do conhecimento relativamente novo, nascida de uma subdisciplina dos estudos da Economia. Segundo o autor, a Economia sempre lhe relegou um papel marginal nos processos de ascensão e declínio econômico. Sen (1983) analisando o trabalho de Hirschman (1981), afirma tratar-se de uma disciplina que desempenha um papel central no campo econômico de países desenvolvidos.

Conforme comenta Bresser-Pereira (1986), a forma mais geral de desenvolvimento econômico é o aumento da renda por habitante, pois essa mede o aumento da produtividade; já os níveis comparativos de desenvolvimento econômico são medidos pela renda em termos PPP (puchasing, power, parity) por habitante, porque a renda avalia melhor a capacidade média de consumo da população do que a renda nominal.

Para o autor, o desenvolvimento econômico sugere uma sociedade capitalista organizada, onde há acumulação de capital de progresso técnico, um mercado coordenando e um estado regulando esse mercado e complementando sua ação coordenadora. $\mathrm{O}$ desenvolvimento econômico visa atender um objetivo fundamental das sociedades modernas: o bem-estar.

\section{Estudos bibliométricos}

A bibliometria, originalmente conhecida como bibliografia estatística, consiste na aplicação de técnicas estatísticas e matemáticas para realizar uma busca de dados com determinado tema em estudo, a fim de analisar quantitativamente as informações contidas nesses estudos. De acordo com Bradford (1949), as pesquisas bibliométricas são estudos específicos a fim de mensurar índices de produção acadêmica.

A pesquisa bibliográfica é feita a partir do levantamento de referências teóricas já analisadas e publicadas por meios escritos e principalmente eletrônicos. Qualquer 
trabalho científico inicia-se com uma pesquisa bibliográfica, que permite ao pesquisador conhecer o que já se estudou sobre o assunto. Existem, porém, pesquisas científicas que se baseiam unicamente na pesquisa bibliográfica, procurando referências teóricas publicadas com o objetivo de recolher informações ou conhecimentos prévios sobre o problema a respeito do qual se procura a resposta (FONSECA, 2002, p. 32).

Segundo Gil (2010), a pesquisa bibliográfica desenvolve-se ao longo de uma série de etapas. Seu número, assim como seu encadeamento, depende de muitos fatores, tais como a natureza do problema, o nível de conhecimentos que o pesquisador dispõe sobre o assunto e o grau de precisão que se pretende conferir à pesquisa.

Como destacado por Foresti (1989), a análise de citações é a área mais importante da bibliometria, pois pode ser definida como a pesquisa das relações entre os documentos citantes e os documentos citados considerados como unidades de análise, no todo ou em diversas partes: autor, título, origem geográfica, ano, idioma de publicação, entre outros.

Esta pesquisa se caracteriza como bibliométrica, com caráter exploratório e descritivo. Conforme Collis e Hussey (2005), a pesquisa exploratória e descritiva é aquela que descreve os comportamentos dos fenômenos e estabelece relações entre as variáveis. O procedimento que norteia o estudo se caracteriza como bibliométrico, que, segundo Vanti (2002), é um procedimento que quantifica a ciência, o qual emprega a aplicação estatística nas fontes de informação, através da aplicação de modelos matemáticos e estatísticos para analisar a comunicação escrita de uma determinada área.

A técnica bibliométrica começou a ser utilizada no início do século XX, sendo que no início era focalizada em medir livros, ou seja, sua utilidade era quantificar exemplares e edições, número de palavras existentes nos livros, informações relacionadas à indústria dos livros, bem como o espaço que os livros ocupavam nas prateleiras. Progressivamente foi revertendo para o estudo de produção bibliográfica, referindo-se a artigos de periódicos e outros tipos de documentos, para depois ocupar-se da produtividade de autores e estudo de citações (ARAÚJO, 2006).

Conforme declara Wormell (1998), para obtenção de maior precisão nos resultados esperados através do estudo bibliométrico são necessários o conhecimento dos critérios que se caracterizam com a pesquisa realizada. Assim, encontram-se na literatura três leis bibliométricas: a de maior utilização, chamada Lei de Lotka, alusiva à produtividade científica; a Lei de Bradford, relacionada à dispersão da produção científica; e a Lei de Zipf, que se refere à ocorrência de palavras no texto. O presente trabalho utiliza-se da Lei de Zipf, também conhecida como Lei do Menor Esforço, a qual reflete a medição da frequência do aparecimento das palavras em diversos artigos (VANTI, 2002). 
Através de indicadores bibliométricos é possível investigar peculiaridades no crescimento cronológico da produção científica, como o viés de pesquisas e autorias em que se identifica o passado e orientações futuras como publicações de assuntos de maior destaque ou relevância em assuntos a serem considerados (SENGUPTA, 1992; BUFREM; PRATES, 2005). Através de acompanhamentos e análises de apontamentos advindos da bibliometria, os objetivos da pesquisa são respondidos, conforme afirma Vanti (2002).

\section{Método de pesquisa}

A bibliometria é uma técnica quantitativa e estatística de medição dos índices de produção e disseminação do conhecimento científico, tal como procede a demografia ao enumerar a população. Surge no início do século como sintoma da necessidade do estudo e da avaliação das atividades de produção e comunicação científica (FONSECA, 1986).

Com a realização de estudos bibliométricos é possível avaliar quantitativamente um conjunto de informações acerca de um grupo de artigos selecionados sobre um determinado tema, assim permitindo a análise preliminar da literatura existente em uma determinada área selecionada em meio a várias possibilidades que permeiam a produção científica (COSTA, 2010).

A bibliometria foi escolhida para a realização deste estudo. Ela foi desenvolvida pelas Ciências da Informação e pela Biblioteconomia e é um método de pesquisa que abrange análises quantitativa, estatística e de visualização de dados para buscar a estrutura do conhecimento de um campo científico, servindo como uma ferramenta para a verificação do comportamento dos pesquisadores quanto às suas decisões na construção do conhecimento (VANTI, 2002).

Optou-se por fazer uma pesquisa bibliométrica sobre os assuntos "capital social" e "desenvolvimento econômico". Verificou-se, após o estudo sobre capital social, que autores apontam para a sua ligação com o desenvolvimento econômico. A pesquisa foi realizada através na base de dados Science Direct, com acesso em outubro de 2016, selecionada por ser uma base reconhecida pela sua relevância na pesquisa acadêmica. Na busca avançada, ao escolhermos "capital social", digitamos o termo "social capital", escolhendo palavras contidas no título, resumo e palavras-chave, com a pesquisa restrita a periódicos, com um retorno de 2.395 artigos. Ao utilizamos o desenvolvimento econômico, digitando "economic development", localizaram-se 7.183 artigos. A grande quantidade de documentos deve-se ao fato da amplitude do tema, que pode ser relacionado com diversos outros assuntos.

A fim de pesquisar o desenvolvimento econômico e capital social tratados conjuntamente, utilizou-se o modelo de busca avançada, onde foram pesquisadas 
as palavras "social capital" AND "economic development" OR "economic growth", selecionando palavras contidas no título, resumo ou palavras-chave. Foi utilizado o termo desenvolvimento econômico ou crescimento econômico devido à similaridade que apresentam. Os termos foram buscados em inglês, por ser o idioma com maior número de publicações científicas. Não foram selecionadas áreas específicas do conhecimento, a fim de obter-se uma maior abrangência para a pesquisa. O período não foi restrito, a fim de verificar-se a evolução das publicações sobre o tema no decorrer dos anos.

O resultado obtido, em outubro de 2016, foi de 76 artigos apresentados. Como diversos artigos não são de livre acesso, sendo necessário a compra do artigo, refez-se a mesma pesquisa, restringindo como artigos de livre acesso, ou "open access". Na busca, retornaram 16 artigos, os quais são a amostra utilizada para o desenvolvimento deste estudo.

Passos para seleção dos artigos:

1. Acesso ao site da Science Direct Elsevier através do endereço website: http://www-sciencedirect-com.ez314.periodicos.capes.gov.br/science/search;

2. Selecionada a aba "ALL";

3. Inserido a palavra de pesquisa "social capital";

4. Selecionada a operação " $A N D$ ”;

5. Inserindo-se os termos "economic development" OR "economic growth";

6. Selecionando os campos em ambas as palavras de pesquisas "título, resumo e palavras-chave" (Abstract, Title, Keywords);

7. Selecionado "Tipo de Material: periódicos" (Journals);

8. Selecionado os artigos de livre acesso, "open access";

9. Selecionada a "Data de publicação: todos" (All Years) - restrito a data da busca até 30/10/2016, para verificarmos como evoluiu a produção sobre os assuntos no tempo;

10. Não foi restringida a área de conhecimento, optando-se por "all sciences", todas as ciências;

11. Selecionada a opção "Buscar" (Search);

Através da análise dos artigos retornados desta busca, objetivou-se verificar quem foram os autores mais citados, a fim de observar os trabalhos que estão sendo mais disseminados no meio acadêmico. A análise das citações fornece aos pesquisadores referências importantes sobre o campo de estudo, além de elucidar quais foram os autores predecessores para a área de conhecimento abordada (CALDAS; TINOCO, 2004). As citações representam a origem ou a 
fundamentação dos conceitos discutidos pelos pesquisadores em seus estudos (CALDAS; TINOCO, 2004).

Analisaram-se os tópicos mais abordados, a fim de destacar quais os principais que foram recorrentes dentro do assunto. Assim, verificou-se o que os pesquisadores desejaram abordar dentro do tema em questão e, também, os resultados mais encontrados nos estudos. Verificaram-se também os idiomas nos quais foram publicados os artigos sobre o tema. Assim, constata-se qual é o idioma de maior volume para a área de pesquisa em questão.

\section{Análise e interpretação de resultados}

$\mathrm{Na}$ análise de autores mais citados, foram identificados sete autores que são citados em pelos menos três dos artigos, conforme Quadro 1. Foram considerados os autores que foram citados por artigo, independentemente do número de citações dentro do mesmo artigo.

\section{Quadro 1 Autores mais citados}

\begin{tabular}{|l|c|c|c|}
\hline \multicolumn{1}{|c|}{ Autor Citado } & $\begin{array}{c}\text { Quantidade de } \\
\text { artigos em que } \\
\text { foi citado }\end{array}$ & $\begin{array}{c}\text { Percentual de } \\
\text { artigos nos quais } \\
\text { foi citado }\end{array}$ & $\begin{array}{c}\text { Ranking de } \\
\text { citações }\end{array}$ \\
\hline Coleman, J. & 6 & $37,5 \%$ & $1^{\circ}$ \\
\hline Putnam, R. & 5 & $31,25 \%$ & $2^{\circ}$ \\
\hline Bourdieu, P. & 3 & $18,75 \%$ & $3^{\circ}$ \\
\hline Barro, R. & 3 & $18,75 \%$ & $3^{\circ}$ \\
\hline Easterlin, R. A. & 3 & $18,75 \%$ & $3^{\circ}$ \\
\hline Helliwell, J. & 3 & $18,75 \%$ & $3^{\circ}$ \\
\hline $\begin{array}{l}\text { La Porta, R.; Lopez-de } \\
\text { Silanes, F.; Shleifer, A.; } \\
\text { Vishny, R. W. }\end{array}$ & 3 & $18,75 \%$ & $3^{\circ}$ \\
\hline
\end{tabular}

Fonte: Elaboração própria, 2016.

Observa-se a relevância do trabalho de James Coleman, sendo citado em 6 dos 16 artigos, com uma representatividade de $37,5 \%$ das obras. Em seguida, Robert Putnam, que foi citado em 5 estudos, representando 31,35\% dos trabalhos. Em seguida, têm-se cinco autores que foram citados em três trabalhos. Ressalta-se o 
autor Pierre Bourdieu, que aparece juntamente com Coleman e Putnam como referência no assunto capital social.

Assim como encontrado neste estudo, os autores Silva, Silva e Silva (2009) apontam em sua pesquisa a relevância de Bourdieu, Coleman e Putnam para o capital social. Elas esclarecem que Bourdieu segue uma abordagem que pode ser classificada como estruturalista quanto às relações que ocorrem entre os agentes; Coleman segue o institucionalismo, ressaltando o papel das instituições e do individualismo, um recurso para as pessoas; e Putnam, que também pode ser classificado como institucionalista. Esses autores evidenciam a relevância das organizações sociais para com o sistema econômico-social (SILVA; SILVA; SILVA, 2009).

Boeira e Borba (2006), na resenha sobre fundamentos do capital social de Higgins, também abordam os autores Bourdieu, Coleman e Putnam. Os autores sintetizam quatro perspectivas sobre o conceito de capital social: a) utilitarista, na qual inclui as abordagens de Coleman; b) estrutural, como a de Bourdieu e neoinstitucionalistas; c) tradicionalista, como a visão de Putnam; d) moralcomunicativa, na qual articula aspectos das obras de Durkheim e de Habermas.

Durston (2002), em seu estudo, destaca três teóricos ligados ao conceito de capital social: Coleman, Putnam e Bourdieu. Segundo ele, James Coleman atua na área da educação, verificando o crescimento do capital humano, com uma abordagem de escolha racional. Robert Putnam aborda o conceito de capital social na participação e engajamento da sociedade e os seus efeitos nas instituições democráticas e na qualidade do governo. Este estudo foi realizado em algumas regiões da Itália. O capital social é abordado como um recurso coletivo baseado nas normas e redes de intercâmbio entre os indivíduos, tanto para Putnam quanto para Coleman.

Os 16 artigos que resultaram da busca na base de dados apresentaram três idiomas distintos. O idioma inglês, embora não coincida com o país de origem de todos os autores, representa a maior quantidade de artigos, com 14 publicações, ou seja, com $87,5 \%$. Para os idiomas espanhol e português localizaram-se um artigo cada $(6,25 \%)$ e apresentam trabalhos desenvolvidos com base na região de origem dos autores. 


\section{Figura 1 Idiomas dos artigos}

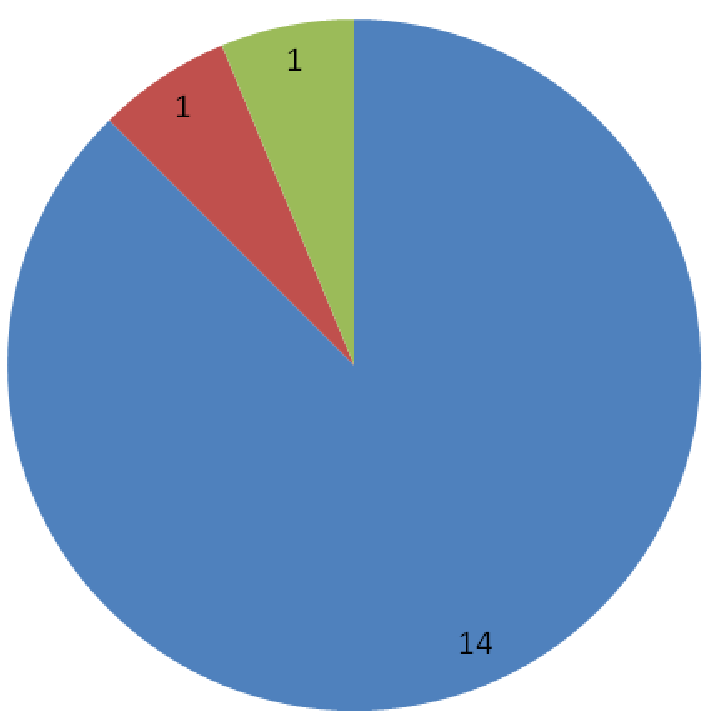

Inglês

Espanhol

Português

Fonte: Elaboração própria, 2016.

Foram localizados cinco tópicos mais presentes nesses artigos, conforme Quadro 2. Os tópicos mais encontrados foram "capital social", que se repetiu em 4 trabalhos e "social", localizado em 3 artigos.

\section{Quadro 2 Tópicos abordados}

\begin{tabular}{|l|c|}
\hline \multicolumn{1}{|c|}{ Tópico } & Quantidade de artigos \\
\hline Capital Social & 4 \\
\hline Social & 3 \\
\hline Ciências Comportamentais & 2 \\
\hline Cultural & 2 \\
\hline GDP (Produto interno bruto) & 2 \\
\hline
\end{tabular}

Fonte: Elaboração própria, 2016.

Verifica-se prevalência de assuntos que abordam fatores culturais e comportamentais e localiza-se o interesse no produto interno bruto (GDP), relacionado ao desenvolvimento econômico. Na Figura 2 estão dispostas as quantidades de artigos por ano de edição. 
Figura 2 Relação de ano de edição

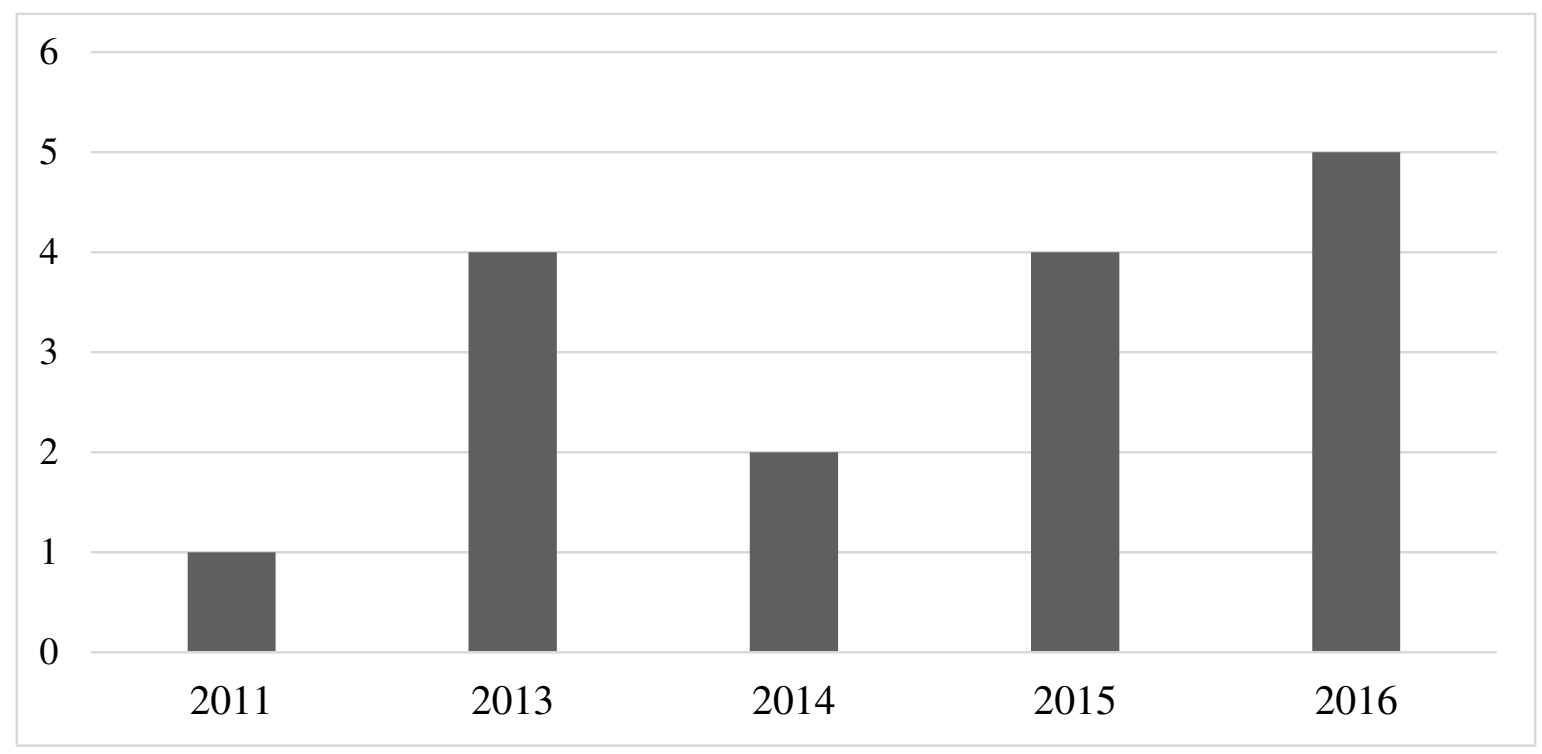

Fonte: Elaboração própria, 2016.

Verifica-se, através da Figura 2, que os assuntos capital social e desenvolvimento passaram a ser abordados em estudos conjuntamente apenas no período recente. A pesquisa realizada na base de dados não restringiu o ano de publicação, sendo que o primeiro artigo verificado nessa busca foi do ano de 2011, contudo, vale ressaltar que a pesquisa foi realizada apenas com artigos de livre acesso. Como apontado na literatura, foi depois dos estudos de Putnam que os assuntos passaram a ser abordados conjuntamente. Verifica-se o crescente interesse pelos temas, uma vez que a produção é crescente, culminando no ápice de 5 artigos em 2016. Na Figura 3 verifica-se a quantidade de autores por artigo. 
Figura 3 Quantidade de autores por artigo

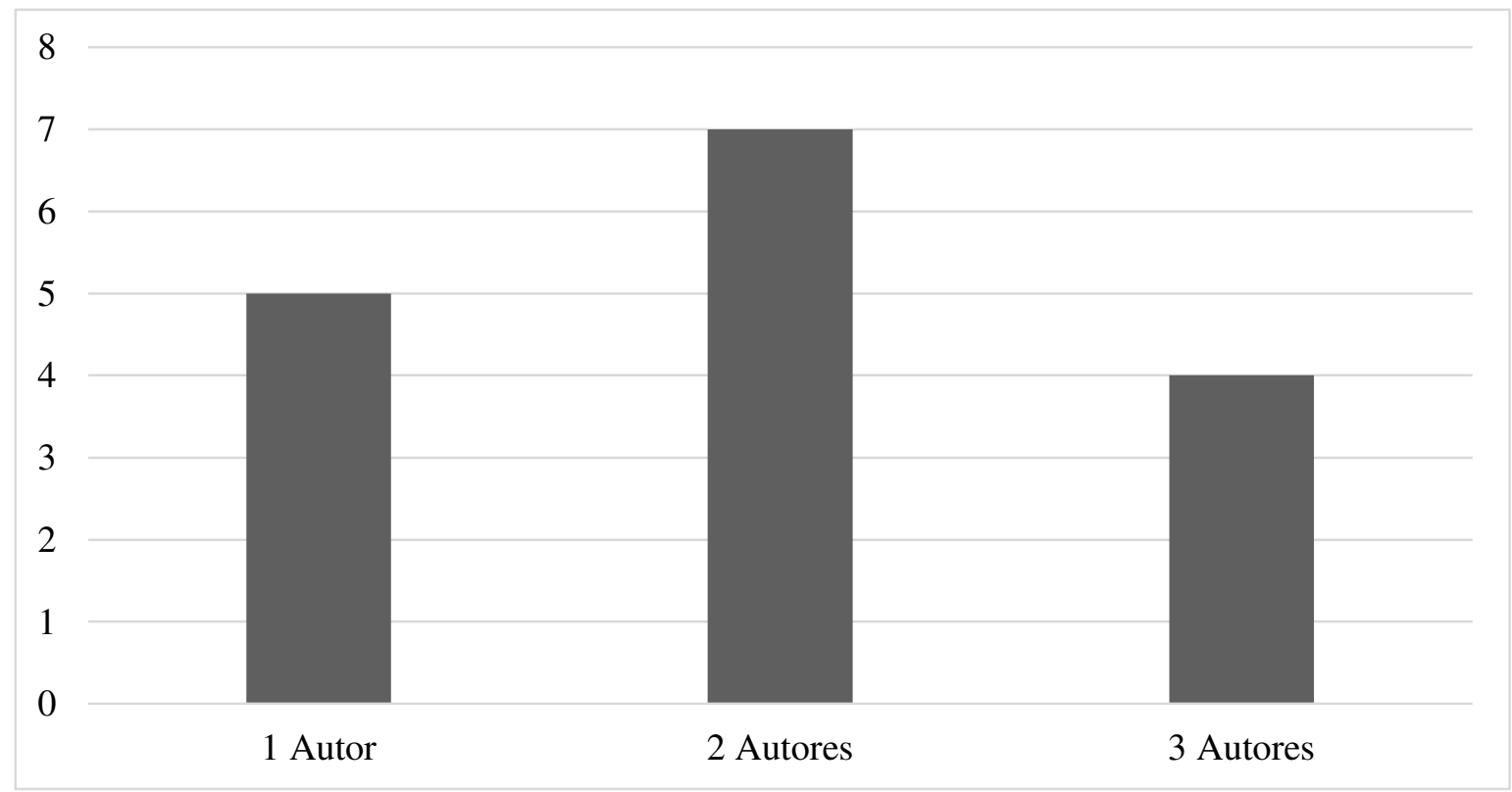

Fonte: Elaboração própria, 2016.

Outro critério observado corresponde à quantidade de autores por artigo. No Brasil, este vem sendo um dos critérios adotados pelas revistas de maior classificação como critério de aceitação dos artigos. É possível observar que a maioria dos trabalhos foi escrita por 2 autores, seguido por um autor, enquanto a menor quantidade de artigos apresenta 3 autores.

$\mathrm{Na}$ Figura 4 apresenta-se a nuvem de palavras-chave que foram traduzidas para o idioma português. 


\section{Figura 4 Nuvem de palavras-chave dos artigos mapeados}

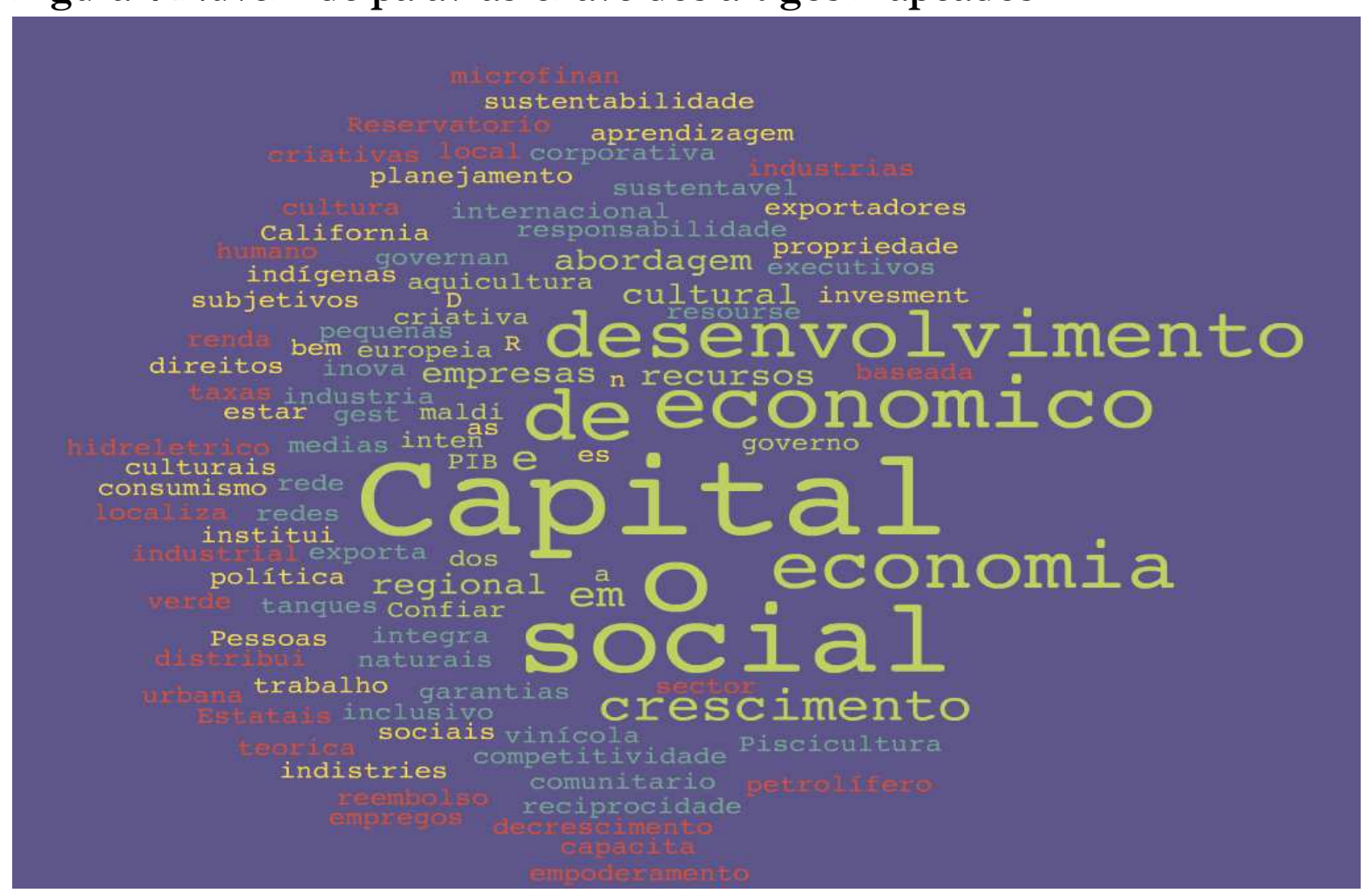

Fonte: Elaboração própria, 2016.

Nota: Elaborado com uso do site http://www.abcya.com.

Foram elencadas as palavras-chave de cada artigo, em que foi possível perceber que as palavras que apareceram com maior frequência foram capital social, em 10 artigos, seguidas por desenvolvimento econômico e crescimento econômico, em 3 documentos cada. Esse resultado pode ser atribuído à pesquisa ter sido realizada com base nesses termos.

\section{Considerações finais}

O objetivo desse estudo foi analisar as publicações científicas sobre os temas capital social e desenvolvimento econômico disponíveis na base de dados Science Direct, devido à relevância dessa base de dados para as pesquisas acadêmicas. Verificou-se, através da literatura pesquisada, que a convergência sobre os temas é recente. Essa integração entre os assuntos ocorreu a partir da definição de Putnam sobre capital social e, a partir de então, o tema passa a ser abordado em estudos sobre o desenvolvimento econômico.

A partir dos resultados desta pesquisa referente ao perfil das publicações sobre os temas abordados, pode-se apresentar algumas considerações. Devido ao tema capital social ser introduzido no pensamento econômico através de Putnam, 
verifica-se a sua contribuição para a interligação desses conceitos. Robert Putnam, em virtude da magnitude do seu trabalho, juntamente com James Coleman e Pierre Bourdieu são os autores mais citados nas obras pesquisadas. O que é ratificado pela literatura, que afirma que os autores Putnam, Bourdieu e Coleman são apontados como referência na construção do saber sobre os temas abordados. Portanto, o presente trabalho corrobora a literatura, atestando a importância destes autores na construção do conhecimento sobre o tema.

Quanto às palavras-chave, verificou que as que apresentaram maior frequência foram capital social, seguido por desenvolvimento econômico e crescimento econômico. Atribui-se a maior frequência destas palavras-chave devido à busca ter sido efetuada com a utilização desses termos. No que tange os tópicos mais mencionados nesses estudos, pode-se citar capital social, social, ciências comportamentais, cultural e produto interno bruto, por comporem as palavras utilizadas na seleção dos artigos, assuntos ligados à cultura e comportamento humanos, juntamente com a parte econômica, representada pelo produto interno.

A prevalência da quantidade de autores foi de dois autores, localizado em sete artigos, sendo que cinco dos artigos estudados foram escritos por um autor e outros quatro artigos foram elaborados por três autores. Através da bibliometria foi possível identificar que se destaca o idioma inglês com $87,5 \%$ das publicações encontradas, o que significa que os pesquisadores da área estão utilizando-se desse idioma para a publicação em periódicos, possivelmente devido à quantidade de literatura disponível nesse mesmo idioma. Verificou-se apenas um artigo em português, demonstrando a carência de estudos nesta área publicados em periódicos com o idioma português.

Como limitações da pesquisa, pode-se apontar fatores como a pesquisa ter sido elaborada utilizando-se apenas uma base de dados, a Science Direct, assim como a extração e a leitura dos artigos que estavam com acesso liberado sem restrições. Sugere-se, como recomendações de pesquisas futuras, abordar outros temas aliados a capital social e desenvolvimento econômico, como cultura, confiança e cooperativismo. Além disso, recomenda-se a replicação da pesquisa com os mesmos temas sobre capital social e desenvolvimento econômico, contudo, em outra base de dados, confrontando os resultados encontrados por este estudo.

\section{Referências}

ADISESHIAH, M. O papel do homem no desenvolvimento. Rio de Janeiro: FGV, 1970.

ALVES, L. B.; BASTOS, R. P. Sustentabilidade em Silvânia (GO): o caso dos assentamentos rurais São Sebastião da Garganta e João de Deus. RERS, Piracicaba, v. 49, n. 2, p. 419-448, abr./jun. 2011. 
ARAÚJO, C. A. Bibliometria: evolução histórica e questões atuais. Em questão, v. 12, n. 1, 2006.

BOEIRA, S. L.; BORBA, J. Os fundamentos teóricos do capital social. Ambiente e Sociedade, v. 9, n. 1, p. 187-193, 2006.

BRADFORD, S. C. Sources on specific subjects. Engineering, Cambridge, v. 37, 85-86, 1949.

BRESSER-PEREIRA, L. C. Lucro, acumulação e crise. São Paulo: Editora Brasiliense, 1986.

BUFREM, L.; PRATES, Y. O saber científico registrado e as práticas de mensuração da informação. Ciência da Informação, v. 34, n. 2, p. 9-25, 2005.

CALDAS, M. P.; TINOCO, T. Pesquisa de gestão em recursos humanos nos anos 1990: um estudo bibliométrico. RAE, v. 44, n. 3, p. 100-114, jul./set. 2004.

COLEMAN, J.S. Social capital in the creation of human capital, American Journal of Sociology, v. 94, p. 95-120, 1988.

COLLIS, J.; HUSSEY, R. Pesquisa em administração: um guia para alunos de graduação e pós-graduação. 2. ed. Porto Alegre: Bookman, 2005.

COSTA, H. G. Modelo para Webibliomining: proposta e caso de aplicação. Revista da FAE, v. 13, p. 115-125, 2010.

DURSTON, J. El capital social campesino en la gestión del desarrollo rural: díadas, equipos, puentes y escaleras. Santiago de Chile: Comisión Económica para América Latina y el Caribe-CEPAL, nov. 2002.

FONSECA, J. J. S. Metodologia da pesquisa científica. Fortaleza: UEC, 2002.

FONSECA, E. N. (Org.). Bibliometria: teoria e prática. São Paulo: Cultrix; Ed. da USP, 1986.

FORESTI, N. Estudo da contribuição das revistas brasileiras de biblioteconomia e ciência da informação enquanto fonte de referência para a pesquisa. 1989. Dissertação (Mestrado) - Departamento de Biblioteconomia da Universidade de Brasília, UnB, Brasília, 1989. 
FREDERKING, L. C. Is there an endogenous relationship between culture and economic development? Journal of Economic Behavior \& Organization, v. 48, p. 105-126, 2002.

GIL, A. C. Como elaborar projetos de pesquisa. 5. ed. São Paulo: Atlas, 2010.

GROOTAERT, C. Social capital: the missing link? (= Social Capital Initiative, Working Paper N. 3). Washington: The World Bank, 1998.

HEWLETT, S. A. Dilemas do desenvolvimento. Rio de Janeiro: Zahar, 1981.

HIRSCHMAN, A. O. Essays in trespassing: economics to politics and beyond. Cambridge: Cambridge University Press, 1981.

LIMA, R. A. S.; SHIROTA, R. Influência do capital social no mercado de crédito rural. RER, Rio de Janeiro, v. 43, n. 1, p. 63-80, jan./mar. 2005.

MARTELETO, R. M.; SILVA, A. B. O. Redes e capital social: o enfoque da informação para o desenvolvimento local. Ciência da Informação, Brasília, v. 33, n. 3, p. 41-49, set./dez. 2004.

MORAES, J. L. A. Capital social e desenvolvimento regional (Editado S. M. D. S. Correa). Santa Cruz do Sul: EDUNISC, p.123-148, 2003.

PORTES, A. Social capital: its origins an applications in modern sociology knowledge and social capital: foundations and applications (Editado L. Lesser). Boston: Butterworth-Heinemann, p. 43-67, 1998.

PUTNAM, R. Comunidade e democracia: a experiência da Itália moderna. Rio de Janeiro: Editora FGV, 1995.

PUTNAM, R. Comunidade e democracia: a experiência da Itália moderna. Tradução Luiz Alberto Monjardim. 3. ed. Rio de Janeiro: Editora FGV, 2002.

SENGUPTA, I. N. Bibliometrics, infometrics, scientometrics and librametrics: an overview. Libri, v. 42, n. 2, p. 99-135, 1992.

SCHUMPETER, Joseph A. Development Economics. Oxford: Oxford University Press, 1961.

SEN, A. Development: which way now? The Economic Journal, v. 93, n. 372, p.745-762, 1983. 
SILVA, S. B. M.; SILVA, B. C. N.; SILVA, M. P. Organização social e indicadores socioeconômicos no Brasil: um estudo exploratório. Caderno CRH, Salvador, v. 22, n. 57, p. 617-633, set./dez. 2009.

SOARES, A. P. A.; ABREU, E. A. P.; NAVAES, A. M. A relação entre o capital social e o desenvolvimento local: o caso das comunidades rurais de baixo rendimento em Pernambuco. Sociedade Brasileira de Economia, Administração e Sociologia Rural, Campo Grande, $48^{\circ}$ Congresso Tecnologia, Desenvolvimento e Integração Social, 2010.

VANTI, N. Da bibliometria à webometria: uma exploração conceitual dos mecanismos utilizados para medir o registro da informação e a difusão do conhecimento. Ciência da Informação, v. 31, n. 2, p. 152-162, 2002.

WORMELL, I. Infometria: explorando bases de dados como instrumentos de análise. Ciência da Informação, v. 27, n. 2, p. 210-216, 1998.

Endereço para correspondência:

Munique Rech_muniquerech@gmail.com

Rua Francisco Getúlio Vargas, 1130

95.070-560 Caxias do Sul/RS, Brasil

RobertoClamer-rclamer@ucs.br

Rua Francisco Getúlio Vargas, 1130

95.070-560 Caxias do Sul/RS, Brasil

Sandra Regina Isoton Terribile - srisoton@ucs.br

Rua Francisco Getúlio Vargas, 1130

95.070-560 Caxias do Sul/RS, Brasil

Janaina Macke_jmacke@terra.com.br

Rua Francisco Getúlio Vargas, 1130

95.070-560 Caxias do Sul/RS, Brasil 